\title{
Rendezvous within biloma technique combining percutaneous and endoscopic approaches: a novel biliary recanalization method
}

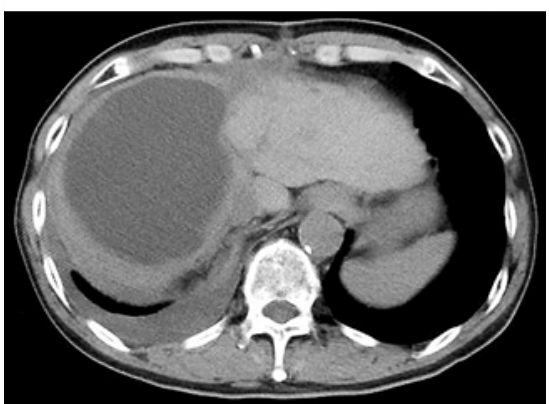

- Fig. 1 Abdominal computed tomography showing a large biloma under the diaphragm.

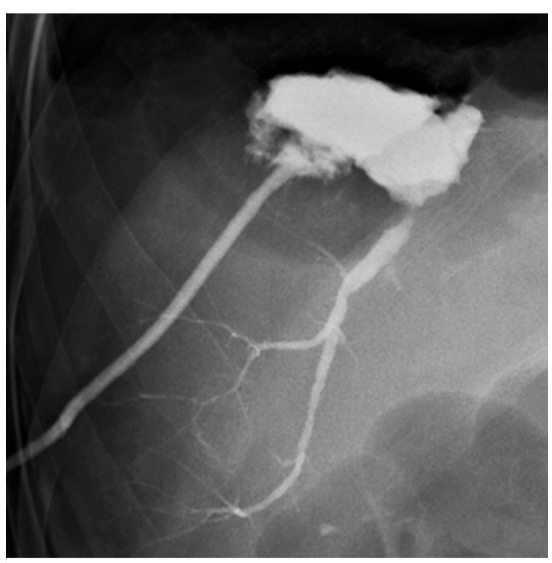

- Fig. 2 Contrast injection from the percutaneous route showing the right intrahepatic $\mathrm{B} 6$ bile duct in communication with the biloma.

Biliary injury and biloma are complications that can occur with hepatobiliary surgery [1]. Endoscopic or percutaneous recanalization for postoperative biliary injury have been reported as minimally invasive treatments [2], but remains challenging for severe biliary stricture [3-5]. Here, we present a case of biliary injury successfully treated by combining endoscopic and percutaneous approaches within the biloma.

A 61-year-old man who underwent partial hepatectomy for hepatocellular car-
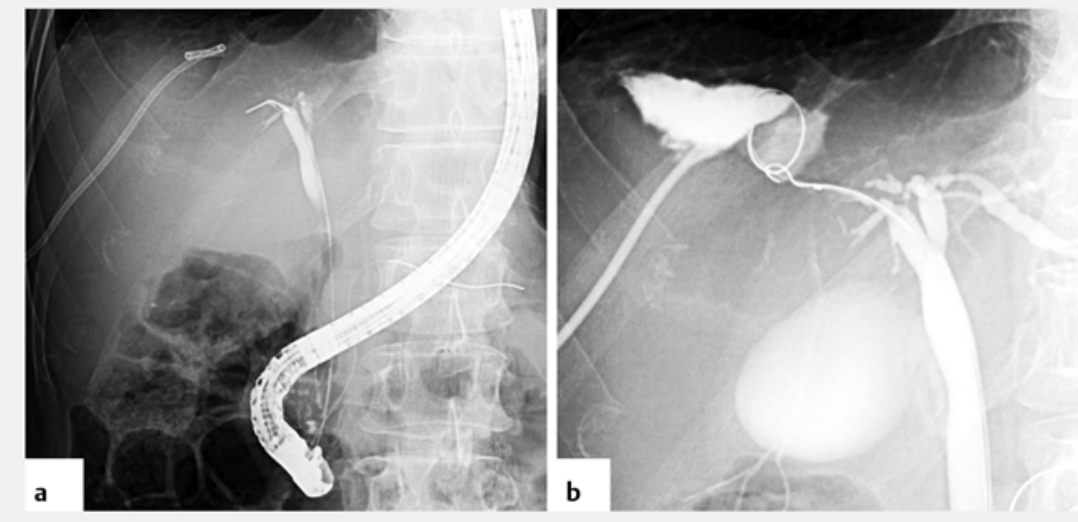

- Fig. 3 Cholangiographic views during endoscopic retrograde cholangiopancreatography showing: $\mathbf{a}$ the disrupted bile duct of the right posterior branch; $\mathbf{b}$ a 0.025 -inch guidewire that could be successfully advanced into the biloma through the stricture but could not be passed through the disrupted $\mathrm{B} 6$.

cinoma presented with high fever and dyspnea. Computed tomography (CT) revealed a large biloma under the diaphragm ( Fig. 1), and percutaneous drainage was performed. Contrast agent injection via the percutaneous route showed a communication between the biloma and the right intrahepatic bile duct ( $\triangleright$ Fig. 2). Biliary recanalization was attempted with endoscopic retrograde cholangiopancreatography (ERCP). Cholangiography showed a disrupted right posterior branch bile duct ( $\$$ Fig.3). A 0.025 -inch guidewire was advanced into the biloma through the stricture but could not be passed through the disrupted B6 bile duct. Percutaneous transhepatic biliary drainage (PTBD) of B6 was performed.

Via the PTBD route, the guidewire could reach the biloma, but not the right hepatic duct. Therefore, rendezvous biliary recanalization within the biloma combining endoscopic and percutaneous approaches was attempted. After coiling the guidewire within the biloma under ERCP guidance, an EN snare (Merit Medi- cal, West Jordan, Utah, USA) designed with three interlaced loops to retrieve objects was inserted via the PTBD route ( $\triangleright$ Fig.4). The guidewire was grasped with the EN snare, guided through B6, and drawn out via the PTBD route. Finally, a 6-Fr plastic stent was placed through the biloma with its tip positioned at B6 ( Fig. 5; Video 1). The PTBD catheter was removed 3 days post-procedure and the patient was discharged without any complications.

This "rendezvous within biloma" technique could be a minimally invasive rescue option when either the percutaneous or endoscopic approach alone is difficult.

Endoscopy_UCTN_Code_TTT_1AR_2AJ

Competing interests

None 


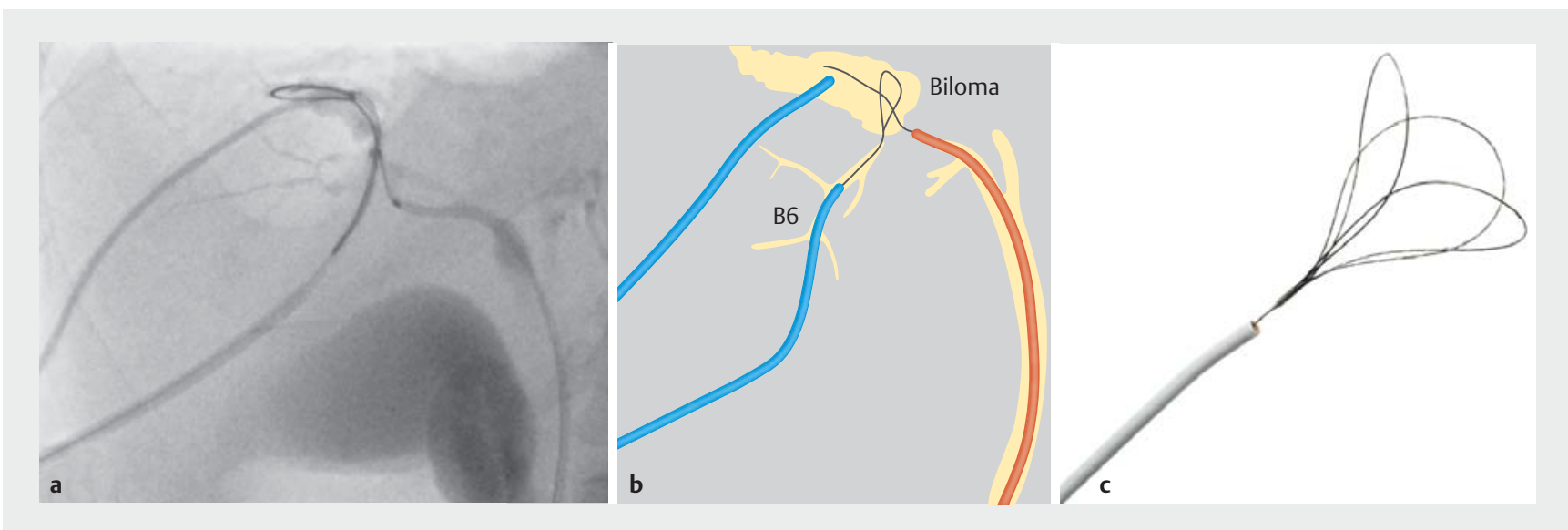

- Fig. 4 The EN snare, which had been inserted via the percutaneous transhepatic biliary drainage route, grasping the guidewire, which had been coiled within the biloma under endoscopic retrograde cholangiopancreatography guidance: a on fluoroscopic view; $\mathbf{b}$ in schematic view. c Photograph of the EN snare showing its three interlaced loops that can be used to retrieve and manipulate foreign objects in the body. Source Fig. 4 c: Merit Medical Systems, INC

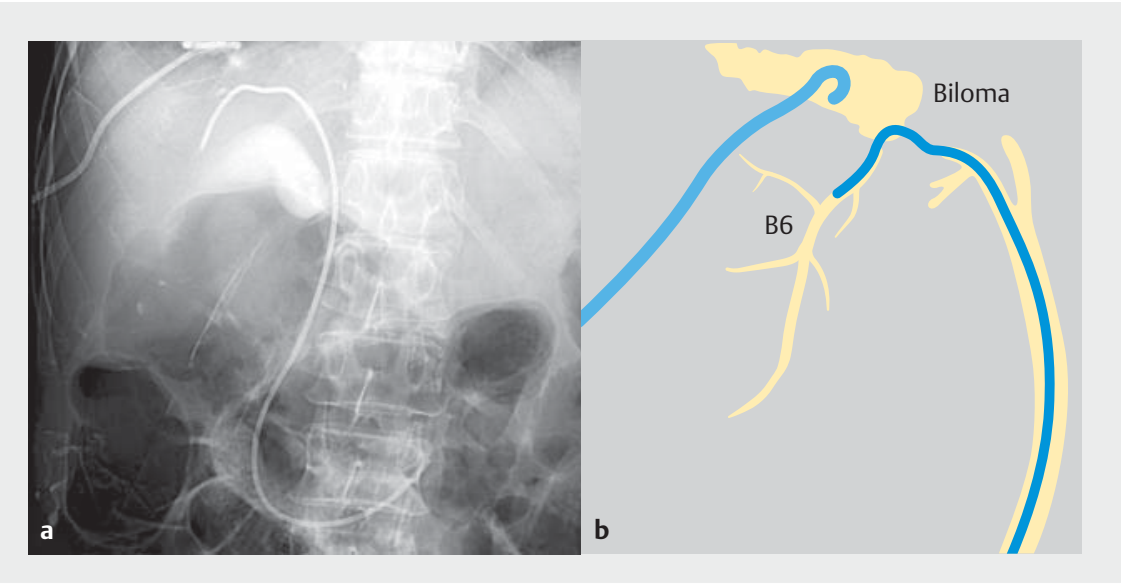

Fig. 5 The 6-Fr plastic stent that had been placed through the biloma with its tip positioned at B6: a on fluoroscopic view; $\mathbf{b}$ in schematic view.

\section{Ayana Okamoto' ${ }^{1}$ Kosuke Minaga' ${ }^{1}$, Mamoru} Takenaka', Tomoe Yoshikawa ${ }^{1}$, Toshimitsu Iwasaki $^{2}$, Masakatsu Tsurusaki ${ }^{3}$, Masatoshi

\section{Kudo ${ }^{1}$}

1 Department of Gastroenterology and Hepatology, Kindai University Faculty of Medicine, Osaka-Sayama, Japan

2 Department of Surgery, Kindai University Faculty of Medicine, Osaka-Sayama, Japan

3 Department of Radiology, Kindai University Faculty of Medicine, Osaka-Sayama, Japan

\section{References}

[1] Lo CM, Fan ST, Liu CL et al. Biliary complications after hepatic resection: risk factors, management, and outcome. Arch Surg 1998; 133: 156 - 161

[2] Yabe S, Kato H, Mizukawa S et al. Predictive factors for outcomes of patients undergoing endoscopic therapy for bile leak after hepatobiliary surgery. Dig Endosc 2017; 29: $353-361$

[3] Jang SI, Rhee K, Kim H et al. Recanalization of refractory benign biliary stricture using magnetic compression anastomosis. Endoscopy 2014; 46: $70-74$

[4] Kawakami H, Abo D, Kawakubo K et al. Rendezvous biliary recanalization combining percutaneous and endoscopic techniques using a diathermic dilator for bile duct obstruction. Endoscopy 2014; 46: E460 -E461

[5] Tonozuka R, Mukai S, Tsuchiya T et al. Recanalization after biliojejunostomy by use of a new digital per-oral cholangioscope through the hepaticogastrostomy route. VideoGIE 2016; 1: 63-65 


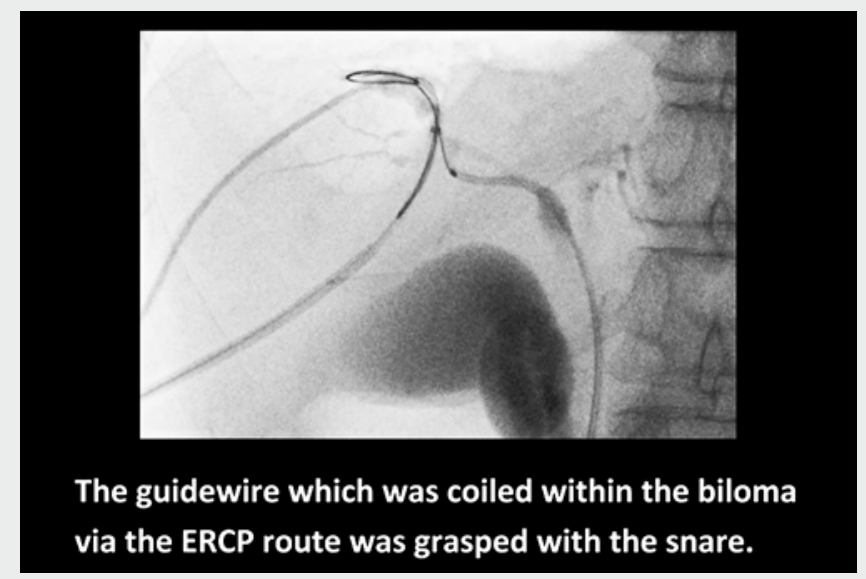

Video 1 The "rendezvous within biloma" technique combining percutaneous and endoscopic approaches was used to treat post-operative biliary injury with biloma. This technique could be a minimally invasive rescue option in patients where either the percutaneous or endoscopic approach alone is difficult.

\section{Bibliography}

DOI https://doi.org/10.1055/a-0800-8216

Published online: 14.12 .2018

Endoscopy 2019; 51: E42-E44

(c) Georg Thieme Verlag KG

Stuttgart · New York

ISSN 0013-726X

\section{ENDOSCOPY E-VIDEOS}

https://eref.thieme.de/e-videos

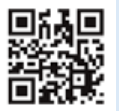

Endoscopy E-Videos is a free access online section, reporting on interesting cases and new

techniques in gastroenterological endoscopy. All papers include a high quality video and all contributions are freely accessible online.

This section has its own submission website at

https://mc.manuscriptcentral.com/e-videos 